\title{
ON TRAPEZOID AND GRÜSS LIKE INTEGRAL INEQUALITIES
}

\author{
B. G. PACHPATTE
}

\begin{abstract}
In the present paper we establish some new integral inequalities similar to that of Trapezoid and Grüss inequalities by using a fairly elementary analysis.
\end{abstract}

\section{Introduction}

The following inequality is well known in the literature as the Trapezoid inequality (see $[6])$ :

$$
\left|\int_{a}^{b} f(x) d x-\frac{f(a)+f(b)}{2}(b-a)\right| \leq \frac{\left\|f^{\prime \prime}\right\|_{\infty}}{12}(b-a)^{3},
$$

the mapping $f:[a, b] \rightarrow R$ is supposed to be twice differentiable on the interval $(a, b)$ with the second derivative bounded on $(a, b)$, that is, $\left\|f^{\prime \prime}\right\|_{\infty}=\sup _{x \in(a, b)}\left|f^{\prime \prime}(x)\right|<\infty$. Another celebrated inequality which gives an estimation for the integral of a product in terms of the product of inegrals, is Grüss inequality (see [5]):

$$
\begin{aligned}
& \left|\frac{1}{b-a} \int_{a}^{b} f(x) g(x) d x-\left(\frac{1}{b-a} \int_{a}^{b} f(x) d x\right)\left(\frac{1}{b-a} \int_{a}^{b} g(x) d x\right)\right| \\
\leq & \frac{1}{4}(M-m)(N-n),
\end{aligned}
$$

where $f, g:[a, b] \rightarrow R$ are two integrable functions such that $m \leq f(x) \leq M$ and $n \leq g(x) \leq N$ for all $x \in[a, b], m, M, n, N$ are constants.

In the recent past, the inequalities (1.1) and (1.2) were studied extensively and numerous generalizations, variants and extensions appeared in the literature, see [1-8] and the references cited therein. The main purpose of this paper is to establish some new inequalities similar to the inequalities given in (1.1) and (1.2). The analysis used in the proofs is elementary and our results provide new estimates on these types of inequalities.

Received June 20, 2002; revised July 30, 2002

2000 Mathematics Subject Classification. 26D15, 26D20.

Key words and phrases. Integral inequalities, Trapezoid and Grüss like inequalities, product of integrals, new estimates, differentiable, identities, absolutely continuous. 


\section{Statement of Results}

Our main results are established in the following theorems.

Theorem 1. $\left(\mathrm{a}_{1}\right)$ Let $f:[a, b] \rightarrow R$ be continuous on $[a, b]$ and differentiable on $(a, b)$, whose derivative $f^{\prime}:(a, b) \rightarrow R$ is bounded on $(a, b)$, i.e. $\left\|f^{\prime}\right\|_{\infty}=\sup _{t \in(a, b)}\left|f^{\prime}(t)\right|<\infty$. Then

$$
\left|\frac{1}{2}\left[f^{2}(b)-f^{2}(a)\right]-\frac{f(b)-f(a)}{b-a} \int_{a}^{b} f(x) d x\right| \leq \frac{1}{3}(b-a)^{2}\left\|f^{\prime}\right\|_{\infty}^{2} .
$$

$\left(\mathrm{a}_{2}\right)$ Let $f:[a, b] \rightarrow R$ be continuous on $[a, b]$ and twice differentiable on $(a, b)$, whose second derivative $f^{\prime \prime}:(a, b) \rightarrow R$ is bounded on $(a, b)$, i.e. $\left\|f^{\prime \prime}\right\|_{\infty}=\sup _{t \in(a, b)}\left|f^{\prime \prime}(t)\right|<$ $\infty$. Then

$$
\begin{aligned}
& \left|\frac{1}{2}\left[f^{2}(b)-f^{2}(a)\right]-\frac{f(b)-f(a)}{b-a} \int_{a}^{b} f(x) d x-\int_{a}^{b}\left(x-\frac{a+b}{2}\right) f^{\prime 2}(x) d x\right| \\
\leq & \frac{1}{b-a}\left\|f^{\prime \prime}\right\|_{\infty} \int_{a}^{b}\left|f^{\prime}(x)\right| B(x) d x,
\end{aligned}
$$

where

$$
B(x)=\int_{a}^{b}|k(x, t)| d t
$$

for $x \in[a, b]$, in which

$$
k(x, t)=\left\{\begin{array}{ll}
\frac{(t-a)^{2}}{2} & \text { if } t \in[a, x] \\
\frac{(t-b)^{2}}{2} & \text { if } t \in(x, b]
\end{array} .\right.
$$

Theorem 2. $\left(\mathrm{b}_{1}\right)$ Let $f, g:[a, b] \rightarrow R$ be continuous on $[a, b]$ and differentiable on $(a, b)$, whose derivatives $f^{\prime}, g^{\prime}:(a, b) \rightarrow R$ are bounded on $(a, b)$, i.e. $\left\|f^{\prime}\right\|_{\infty}=$ $\sup _{t \in(a, b)}\left|f^{\prime}(t)\right|<\infty,\left\|g^{\prime}\right\|_{\infty}=\sup _{t \in(a, b)}\left|g^{\prime}(t)\right|<\infty$. Then

$$
\begin{aligned}
& \left|\frac{1}{b-a} \int_{a}^{b} f(x) g(x) d x-\left(\frac{1}{b-a} \int_{a}^{b} f(x) d x\right)\left(\frac{1}{b-a} \int_{a}^{b} g(x) d x\right)\right| \\
\leq & \frac{1}{2(b-a)^{2}} \int_{a}^{b}\left(\left\|f^{\prime}\right\|_{\infty}|g(x)|+\left\|g^{\prime}\right\|_{\infty}|f(x)|\right) E(x) d x,
\end{aligned}
$$

where

$$
E(x)=\frac{1}{4}(b-a)^{2}+\left(x-\frac{a+b}{2}\right)^{2},
$$

for $x \in[a, b]$.

$\left(\mathrm{b}_{2}\right)$ Let $f, g:[a, b] \rightarrow R$ be continuous on $[a, b]$ and twice differenetiable on $(a, b)$, whose second derivatives $f^{\prime \prime}, g^{\prime \prime}:(a, b) \rightarrow R$ are bounded on $(a, b)$, i.e. $\left\|f^{\prime \prime}\right\|_{\infty}=$ 
$\sup _{t \in(a, b)}\left|f^{\prime \prime}(t)\right|<\infty,\left\|g^{\prime \prime}\right\|_{\infty}=\sup _{t \in(a, b)}\left|g^{\prime \prime}(t)\right|<\infty$. Then

$$
\begin{aligned}
\mid \frac{1}{b-a} \int_{a}^{b} f(x) g(x) d x & -\left(\frac{1}{b-a} \int_{a}^{b} f(x) d x\right)\left(\frac{1}{b-a} \int_{a}^{b} g(x) d x\right) \\
& -\frac{1}{2(b-a)} \int_{a}^{b}\left(x-\frac{a+b}{2}\right)(f g)^{\prime}(x) d x \mid \\
\leq & \frac{1}{2(b-a)^{2}} \int_{a}^{b}\left(\left\|f^{\prime \prime}\right\|_{\infty}|g(x)|+\left\|g^{\prime \prime}\right\|_{\infty}|f(x)|\right) B(x) d x,
\end{aligned}
$$

where $B(x)$ is defined by $(2.3)$.

\section{Proof of Theorem 1}

From the hypotheses on $f$ in $\left(a_{1}\right)$ and $\left(a_{2}\right)$ respectively, we note that, the following identities hold (see [3, p.69] and [2, p.55]):

$$
\begin{aligned}
& f(x)=\frac{1}{b-a} \int_{a}^{b} f(t) d t+\frac{1}{b-a} \int_{a}^{b} p(x, t) f^{\prime}(t) d t \\
& f(x)=\frac{1}{b-a} \int_{a}^{b} f(t) d t+\left(x-\frac{a+b}{2}\right) f^{\prime}(x)-\frac{1}{b-a} \int_{a}^{b} k(x, t) f^{\prime \prime}(t) d t
\end{aligned}
$$

for all $x \in[a, b]$, where

$$
p(x, t)=\left\{\begin{array}{ll}
t-a & \text { if } t \in[a, x] \\
t-b & \text { if } t \in(x, b]
\end{array},\right.
$$

and $k(x, t)$ is defined by $(2.4)$.

(a $\left.a_{1}\right)$ Multiplying (3.1) by $f^{\prime}(x)$ and integrating the resulting identity from $a$ to $b$ we have

$$
\begin{aligned}
& \frac{1}{2}\left[f^{2}(b)-f^{2}(a)\right] \\
= & \frac{1}{b-a}\left(\int_{a}^{b} f(t) d t\right)(f(b)-f(a))+\frac{1}{b-a} \int_{a}^{b} f^{\prime}(x)\left(\int_{a}^{b} p(x, t) f^{\prime}(t) d t\right) d x .
\end{aligned}
$$

From (3.3) we observe that

$$
\begin{aligned}
& \left|\frac{1}{2}\left[f^{2}(b)-f^{2}(a)\right]-\frac{f(b)-f(a)}{b-a} \int_{a}^{b} f(x) d x\right| \\
\leq & \frac{1}{b-a} \int_{a}^{b}\left|f^{\prime}(x)\right|\left(\int_{a}^{b}|p(x, t)|\left|f^{\prime}(t)\right| d t\right) d x \\
\leq & \frac{1}{b-a}\left\|f^{\prime}\right\|_{\infty}^{2} \int_{a}^{b}\left(\int_{a}^{b}|p(x, t)| d t\right) d x .
\end{aligned}
$$


Now, observe that

$$
\begin{aligned}
\int_{a}^{b}|p(x, t)| d t & =\int_{a}^{x}(t-a) d t+\int_{x}^{b}(b-t) d t \\
& =\frac{(x-a)^{2}+(b-x)^{2}}{2}=\frac{1}{4}(b-a)^{2}+\left(x-\frac{a+b}{2}\right)^{2} .
\end{aligned}
$$

Using (3.5) in (3.4) and simple calculation yields the required inequality in (2.1).

$\left(\mathrm{a}_{2}\right)$ Multiplying (3.2) by $f^{\prime}(x)$ and integrating the resulting identity from $a$ to $b$ we have

$$
\begin{aligned}
\frac{1}{2}\left[f^{2}(b)-f^{2}(a)\right]= & \frac{f(b)-f(a)}{b-a} \int_{a}^{b} f(t) d t+\int_{a}^{b}\left(x-\frac{a+b}{2}\right) f^{\prime 2}(x) d x \\
& -\frac{1}{b-a} \int_{a}^{b} f^{\prime}(x)\left(\int_{a}^{b} k(x, t) f^{\prime \prime}(t) d t\right) d x .
\end{aligned}
$$

From (3.6) we observe that

$$
\begin{aligned}
& \left|\frac{1}{2}\left[f^{2}(b)-f^{2}(a)\right]-\frac{f(b)-f(a)}{b-a} \int_{a}^{b} f(x) d x-\int_{a}^{b}\left(x-\frac{a+b}{2}\right) f^{\prime 2}(x)\right| \\
\leq & \frac{1}{b-a} \int_{a}^{b}\left|f^{\prime}(x)\right|\left(\int_{a}^{b}|k(x, t)|\left|f^{\prime \prime}(t)\right| d t\right) d x \\
\leq & \frac{1}{b-a}\left\|f^{\prime \prime}\right\|_{\infty} \int_{a}^{b}\left|f^{\prime}(x)\right| B(x) d x .
\end{aligned}
$$

This completes the proof of the inequality (2.2).

\section{Proof of Theorem 2}

From the hypotheses on $f, g$ respectively in $\left(b_{1}\right)$ and $\left(b_{2}\right)$, we note that the identities (3.1) and (3.2) hold and the following identities corresponding to the function $g$ also hold:

$$
\begin{aligned}
& g(x)=\frac{1}{b-a} \int_{a}^{b} g(t) d t+\frac{1}{b-a} \int_{a}^{b} p(x, t) g^{\prime}(t) d t \\
& g(x)=\frac{1}{b-a} \int_{a}^{b} g(t) d t+\left(x-\frac{a+b}{2}\right) g^{\prime}(x)-\frac{1}{b-a} \int_{a}^{b} k(x, t) g^{\prime \prime}(t) d t,
\end{aligned}
$$

for all $x \in[a, b]$, where $p(x, t)$ and $k(x, t)$ are as explained in the proof of $\left(\mathrm{a}_{1}\right)$.

$\left(\mathrm{b}_{1}\right)$ Multiplying (3.1) by $g(x)$ and (4.1) by $f(x)$, adding and then integrating the resulting identity from $a$ to $b$ we have

$$
\begin{aligned}
2 \int_{a}^{b} f(x) g(x) d x= & \frac{2}{b-a}\left(\int_{a}^{b} f(t) d t\right)\left(\int_{a}^{b} g(x) d x\right) \\
& +\frac{1}{b-a} \int_{a}^{b}\left[g(x) \int_{a}^{b} p(x, t) f^{\prime}(t) d t+f(x) \int_{a}^{b} p(x, t) g^{\prime}(t) d t\right] d x
\end{aligned}
$$


From (4.3) we observe that

$$
\begin{aligned}
& \left|\frac{1}{b-a} \int_{a}^{b} f(x) g(x) d x-\left(\frac{1}{b-a} \int_{a}^{b} f(x) d x\right)\left(\frac{1}{b-a} \int_{a}^{b} g(x) d x\right)\right| \\
\leq & \frac{1}{2(b-a)^{2}} \int_{a}^{b}\left(|g(x)| \int_{a}^{b}|p(x, t)|\left|f^{\prime}(t)\right| d t+|f(x)| \int_{a}^{b}|p(x, t)|\left|g^{\prime}(t)\right| d t\right) d x \\
\leq & \frac{1}{2(b-a)^{2}} \int_{a}^{b}\left(\left\|f^{\prime}\right\|_{\infty}|g(x)|+\left\|g^{\prime}\right\|_{\infty}|f(x)|\right) E(x) d x .
\end{aligned}
$$

This completes the proof of the inequality (2.5).

The proof of $\left(b_{2}\right)$ can be completed by following the proof of $\left(b_{1}\right)$ and closely looking at the proof of $\left(\mathrm{a}_{2}\right)$ given above. Here we omit the details.

In a recent paper [4, p.232], Dragomir and Sofo proved an interesting integral identity. Based on this identity, one can very easily establish the inequalities of the type given in Theorems 1 and 2. Since the formulations of such results are quite straightforward in view of the results given above, here we do not discuss the details.

\section{Acknowledgement}

I would like to express my sincere thanks to the referee for his valuable suggestions which improved the presentation of our results.

\section{References}

[1] K. E. Atkinson, An Introduction to Numerical Analysis, Wiley and Sons (second edition), 1989.

[2] P. Cerone, S. S. Dragomir and J. Roumeliotis, An inequality of Ostrowski type for mappings whose second derivatives belong to $L_{1}(a, b)$ and applications, RGMIA Research Report Collection 1(1998), 53-60.

[3] S. S. Dragomir and N. S. Barnett, An Ostrowski type inequality for mappings whose second derivatives are bounded and applications, RGMIA Research Report Collection 1(1998), 6977 .

[4] S. S. Dragomir and A. Sofo, An integral inequality for twice differentiable mappings and applications, RGMIA Research Report Collection 2(1999), 229-240.

[5] D. S. Mitrinović, J. E. Pečarić and A. M. Fink, Classical and New Inequalities in Analysis, Kluwer Academic Publishers, Dordrecht, 1993.

[6] D. S. Mitrinović, J. E. Pečarić and A. M. Fink, Inequalities Involving Functions and Their Integrals and Derivatives, Kluwer Academic Publishers, Dordrecht, 1994.

[7] B. G. Pachpatte, On Grüss type integral inequalities, J. Inequal. Pure and Appl. Math. 3(2002), Art. 11.

[8] B. G. Pachpatte, On Grüss type inequalities for double integrals, J. Math. Anal. Appl. 267(2002), 454-459.

57 Shri Niketan Colony, Aurangabad 431 001, (Maharashtra), India. 